\title{
Evaluation of the potential of volcanic rock waste from southern Brazil as a natural soil fertilizer
}

Ramos, Claudete Gindri; Querol, Xavier; Celimar Dalmora, Adilson; De Jesus Pires, Karen Cristina; Homrich Schneider, Ivo André; Silva Oliveira, Luis Felipe; Müller Kautzmann, Rubens.

\begin{abstract}
This study was developed to evaluate the chemical and mineralogical properties of acid volcanic rock waste from mining activities by measuring the availability of macronutrients and micronutrients in Milli-Q water, and in acidic solutions to evaluate the potential use of this type of waste as natural soil fertilizers. The sample used in this work was obtained from a company of the mining district of Nova Prata, Rio Grande do Sul State, southern Brazil. Petrographic studies using conventional optical microscopy and scanning electron microscope allowed to define the mineral composition of in powder wastes as being comprised mainly by pyroxene, feldspar, and variable contents of amorphous glass in matrix. The primary oxides detected in the samples by X-ray Fluorescence were calcium oxide, silicon dioxide, aluminium oxide, iron oxide, and with concentration minor potassium oxide, and phosphorus oxide. Several important nutrients were transferred into the acidic solutions, indicating the significant potential and feasibility of these wastes to be effectively used as natural fertilizers. This study is of great relevance to the sector of mining and to agriculture in the region because it can create an alternative disposal treatment for tailings, and improve the environmental sustainability of local farms, thereby avoiding excessive chemical fertilizer consumption.
\end{abstract}

\section{Keywords}

Mining waste, Natural soil fertilizers, Safe environmental, Volcanic rock powders. 